\title{
Covert Assessment of the Family System: Patterns, Pictures and Codes
}

\author{
Linda G. Bell \\ Indiana University Purdue University \\ Indianapolis
}

\author{
David C. Bell \\ Indiana University Purdue University \\ Indianapolis
}

\begin{abstract}
Covert measures of the family system can tap concepts and discover patterns of which family members themselves are unaware and can avoid social desirability bias. Covert measures can be particularly useful in cross-cultural research and can avoid many pitfalls of language and translation. Three such measures which have been used cross-culturally are described. The first is a method of measuring triangulation of children by the parents based on patterns of agreement in a true-false questionnaire describing the family. The second is a projective measure in which family members as a group create a picture of their family distinguishing relationships between individuals and boundaries within and around the family. The third is a global coding scheme used to evaluate family processes from taped interaction.
\end{abstract}

Key words: family assessment; covert measures; cross-cultural comparisons

Families are complex social systems. Many concepts that describe individuals, like height, gender, race, even happiness, can be reasonably easily seen and measured. Family systems concepts, on the other hand, are less directly observed and measured. Some of these family concepts may be recognized within the culture. When the culture gives prominence to a concept, people within that culture can readily recognize and report on this concept (Baldwin, 1992), like the way U.S. families are attuned to individuality and independence, or Japanese families are attuned to interdependency and context. Other concepts are more difficult for family members to see--and for researchers to measure--when the culture does not call attention to them, like boundaries or a concept like positive dependency (Doi, 1981). Creative, careful overt measurement can still be possible, but when transparent, overt measures cannot be relied upon or when subjects are unable or unwilling to report honestly or completely, measures which are less transparent, or covert, can be of value.

In this paper we describe some covert measures developed during a 40-year cross-cultural research project based on structured whole-family interviews conducted in family homes with families of adolescents in the U.S. and Japan. We first review issues involving the measurement of family concepts and suggest how covert measures low in transparency can ameliorate some concerns. We then describe the family systems theory informing this research and give three examples of different kinds of covert measures we have used, one based on patterns of agreement on a 
questionnaire, one a projective family measures, and one a global coding of family interaction processes.

\section{Family Concepts and Measurement Transparency}

Family systems theory views the family as a system which maintains relationships within the family and between the family and the outside world (White, Klein, \& Martin, 2015). The goal of a family social scientist is to be able to test hypotheses derived from theory using measures operationalized from theoretical constructs (Carlson, 2001). The goal of a family therapist or a family life educator is to illuminate family dynamics in a clinically useful way. Formal family assessment can provide valuable information about the family system to supplement a clinician's perceptions. Family assessments can also be informative for family members and help shift the problem focus from the individual to the family (Bray, 1995). Theoretical variables include such family system qualities as communication, overt or covert conflict, problem solving, cohesion, affect and emotion, intimacy, differentiation and individuation, stress, roles, and triangulation, that is, pulling a third person into a relationship system to moderate tension in that system.

A wide variety of self-report and observational methods have been employed to meet the needs of the family scientist and the family therapist or educator (Sherman \& Fredman, 2013; Touliatos, Perlmutter, \& Straus, 1990; Touliatos, Perlmutter, Strauss, \& Holden, 2001). Family measures have been included in studies of marriage (Gottman, 2013), family (Paley, Cox, \& Kanoy, 2001), parent-child relationships (Russell, Mize, \& Saebel, 2001), adult child-elder parent relationships (V. L. Bengtson \& Lovejoy, 1973), family of origin (Bray, Williamson, \& Malone, 1984), and multigenerational patterns (Clingempeel, Colyar, Brand, \& Heatherington, 1992). Methods include self-report (Olson, 1986; Pinsof et al., 2005), case studies (Chodorow, 1993), projective tasks (Bricklin, 1992; Sotile, Julian, Henry, \& Sotile, 1988) and observed structured tasks for family members from which family variables are coded using global coding schemes (e.g., Gottman \& Krokoff, 1989; Grotevant \& Cooper, 1986; Melby \& Conger, 2001; Rueter \& Conger, 1995) and Q-Sorts (P. L. Bengtson \& Grotevant, 1999). Observational methods allow direct assessment of family interaction patterns. Family tasks include such things as focusing on solving a problem or disagreement, or planning a family vacation. Different tasks pull for different family qualities (Melby, Ge, Conger, \& Warner, 1995). Diary designs (Larson \& Almeida, 1999; Laurenceau \& Bolger, 2005) and in-home naturalistic observation (Bronstein et al., 1996; Jacob, Tennenbaum, Bargiel, \& Cseilhamer, 1995; Steinglass, 1980) have advantages similar to task-evaluated global coding or rating scales. 
As researchers seek to understand family life, there is a transparency continuum on which we can compare measures with which we operationalize family systems concepts. At one end are highly transparent overt measures for which we assume that family members understand the theoretical concept in the same way the researcher understands it and are willing to respond directly in accordance with that understanding. How much conflict is there in your family? How close is your relationship with your father? In these cases a transparent measure is useful and convenient. In family studies, as in social science in general, self-report measures predominate, e.g. the Family Environment Scale (Moos, 1974), FACES (Olson, 2002), and the McMaster Family Assessment Device (Miller, Epstein, Bishop, \& Keitner, 1985). Such measures with a high degree of transparency are easy to administer. They provide study participants with a familiar task and are easy to score. For example, in the Family Environment Scale item "We really get along well with each other" (Moos, 1974), family members realize that the researcher is asking about harmony in the family and are able to express their agreement or disagreement with the item. The transparency of the item, the extent to which the content of the item corresponds to the concept being measured, aids in valid measurement. It is common for researchers to use overt individual self-reports to measure a family concept by averaging the family members' scores (Fisher, Kokes, Ransom, Phillips, \& Rudd, 1985).

\section{Awareness and Bias}

However, many concepts of interest to family researchers are concepts that family members do not know and which they cannot directly express. This includes concepts such as power, where family members may not perceive the complexity of influence, the existence of family subsystems or boundaries beyond the easily recognized parent and child subsystems, or structures of conflict. The researcher may be exploring a theoretical 'map' outside of the awareness of family members.

Family member awareness of a family concept is particularly problematic in cross-cultural research. The U.S. itself is an evolving multicultural nation, a nation of multiple minorities, and while there is a scientific interest in theory-derived evaluation, there is also a need to explore the amazing diversity in ethnicity, social class, and family structure (Davenport-Pollock, Kazman, \& Deuster, 2014; Fouts, Roopnarine, Lamb, \& Evans, 2010; Hardy \& Laszloffy, 1995; McGlodrick, Giordano, \& Garcia-Preto, 2005; M. McGoldrick et al., 2004; Murry, Smith, \& Hill, 2001). This interest is reflected in Coontz's recent call for "researchers to move away from looking at the average outcome of various family structures and relationships and spend more time studying the variations, outliers, and divergent responses within each category" 
(Coontz, 2015, p. 12). The search for basic or universal patterns needs to continue with a growing awareness of the importance to carefully include an exploration of this diversity.

When attempting to measure the same concept in two cultures or subcultures, families in each culture will have their own culture-informed understandings. Yet theory-derived measures inherently assume crosscultural comparability by imposing the investigator's conceptual categories on the measurement (Berry, 1969, 1989). The complex cultural context of any idea or behavior precludes any certainty of concepts being identical. Also, even if we could establish the identical concept in two cultures, valid cross-cultural comparison requires that this concept be equally measured in both cultures. It is virtually impossible to establish that a given set of observable behaviors-such as responses to a measurement scale-measure the target concept with the same degree of accuracy in both cultures (L. G. Bell et al., 2004, p 351). Back translation cannot completely deal with this issue.

Van de Vijver and Leung review the kinds of bias which can hamper cross-cultural research or comparative studies involving different ethnic groups within a single country (1997). Typical problems in cross-cultural research are discussed and solutions proposed. They focus on the constructs examined (construct bias), administration procedures (method bias), and operationalizations (item bias). Examples of construct bias would include different meanings of a given measure in the two cultures or poor sampling (e.g., instruments are too short to sample all relevant behaviors). An example of method bias is shown by differential levels of social desirability or differential stimulus familiarity, as well as interviewer effects. Item bias includes poor item translation or inappropriate item content (meaningful for only one group). They note the impossibility of directly comparing cultures when an instrument measures essentially different constructs in two groups, and stress the importance of involving a cross-cultural team of equals at the outset of a study, when theory is developed and constructs are initially designated or designed. See also L.G. Bell et al. (2004).

Even working within a single culture, using transparent measures where family members have a clear or even vague understanding shared with the researcher, reactive effects can still challenge validity. These include social desirability, if some or all family members are intent on showing their family in a good light, and role selection, the process of selecting among several true self-presentations in order to be appropriate in the given situation (Webb, Campbell, Schwartz, \& Sechrest, 1966). Even transparent measures can be compromised by bias from mood and memory (D. C. Bell \& Bell, 2015). Although memory bias may be less for reports of the recent family system, mood bias may be stronger for recent memories (Salovey \& Singer, 1989; Singer \& Salovey, 1988). 


\section{Covert Measures}

When family members are not aware of the researcher's concept, or when family members may be passively reluctant or actively opposed to providing an honest answer, covert, less transparent measures may be useful (Ransom, Fisher, Phillips, Kokes, \& Weiss, 1990). In the case of family members' lack of awareness of the researcher's theoretical concept, the researcher will need to operationalize the concept in a way that does not depend on the family's awareness.

Examples of covert measures include purely projective measures, response patterns or amount of agreement among family members on a questionnaire. Covert measures can include unobtrusive behavioral observation. How often do family members make eye contact during a conversation (as a measure of cohesion or connection)? When Mom speaks, who in the family speaks next (as a measure of power or assertiveness)? Family members' behavior during a problem-solving task can be coded as "uncooperative," "denying responsibility for the problem," or "offering workable solutions" (Rueter \& Conger, 1995). Patterns of agreement on a family description questionnaire can uncover coalitions within the family. Covert measures provide the researcher an opportunity for the respondent to communicate information that the respondent does not consciously know. Thus covert measures can minimize self-knowledge effects, dishonesty effects, and bias effects (Webb et al., 1966). For example, neither the child nor the parent knows that their attachment style is being measured in the Strange Situation (Ainsworth, 1979).

Transparent measures are quite desirable and suitable for large representative samples at relatively low cost. Covert measures on the other hand, including those discussed in this paper, may be expensive to administer, either involving a large time commitment by family participants or by research staff during or after data collection, or both (Lindahl, 2001). Some of the methods described here may be less useful and prohibitively expensive in large samples because of the resources required for administration or coding.

Non-transparent measures can be particularly helpful in cross-cultural research. The cross-cultural research reported here focuses on Japan and the United States. Investigators who have described the culture of the United States have generally emphasized the importance of individuality (Hsu, 1985; Roland, 1988), suggesting a priority placed on individuation. A "nation of immigrants," Americans value independence and selfreliance, the ability to cut connections, to stand alone. U. S. heroes hold their own against group pressure. In families, such mundane patterns as American individual sleeping arrangements emphasize self-reliance and separation: children, even at the youngest ages, almost never sleep with 
parents (Thevenin, 1987). Childhood socialization practices in the United States are seen to promote personal autonomy and individuality (Maccoby \& Jacklin, 1974; Regalia, Manzi, \& Scabini, 2013; Sampson, 2001).

Markus and Kitayama (1991) give a clear description of the differences between the individualistic/independent focus of U.S. culture and the interdependent/collectivist focus in many Asian cultures, including Japan, where the emphasis is on relating to others, attending to others, fitting in, and managing one's own behavior in order to support mutuality. Descriptions of Japanese culture emphasize the importance of relationships (Colman, 1976; Lebra, 1976). Mutual dependency (amae) is self-evident to Japanese, and there is a very high value placed on harmony in the group (L. G. Bell, 1989; Doi, 1981; Kawai, 1988; Lebra, 1976; Nomura, Noguchi, Saito, \& Tezuka, 1995; Tamura \& Lau, 1992). Within a collectivist culture, individuals are more likely to experience themselves, not as separate entities, but as parts of an extended web of relationships (De Vos, 1993; Doi, 1981; Eisler, 1987; Epstein, 1988; Gilligan, 1982; Roland, 1988). Caudill and Weinstein (1969) find that parental touching of and vocalizations to a Japanese infant are indicative of connection and togetherness. Co-sleeping arrangements in Japan, where parents sleep with children, are seen to promote harmony and strong relationships (Caudill \& Plath, 1986; Dore, 1958; Vogel, 1963).

These gross cultural differences can be misleading because neither culture is either one-dimensional or homogeneous. Both U.S. and Japanese cultures value and express both individuation and connection, although in differing ratios. Within Japan, the younger generations appears to be more individualistic than the older (Matsumoto, 2002). Within the U.S., European Americans are more individualistic than other subcultures (Oyserman, Coon, \& Kemmelmeier, 2002) and within U.S. culture, individuality is a stronger theme for men than it is for women (L. G. Bell, Bell, Nakata, \& Bell, 1996). Women, compared to men, have been described as being concerned with connection and with preserving relationships (Eisler, 1987; Roland, 1988; Tannen, 1990): mutual concern is considered to be more important than winning.

\section{Connection and Individuation in the Family System}

The distinction between connection and individuation has been a central focus of the systemic model informing all of the research presented in this paper. The family connection process as we conceptualize it focuses on affection and nurtures self-esteem; the family individuation process focuses on respect and nurtures a differentiated self-concept and personal autonomy.

Family connection. Children, like adults, have a fundamental need to be cherished and nurtured (Baumeister \& Leary, 1995; Belsky, 1981; 
Simpson \& Rholes, 2015). The basis for this need has been identified as an attachment circuit in the brains of all mammals which, in humans, motivates the desire for physical contact and emotional support (Bowlby, 1969/1982; Mikulincer \& Shaver, 2007). The complementary process of caregiving is motivated by a separate brain circuit active in the parent (D. C. Bell, 2001; Panksepp, 1998). We conceptualize the dynamic complementarity of caregiving and attachment as a connection relationship (see Figure 1). When the parent's caregiving is matched with the child's attachment, a family connection relationship emerges that is based on warmth and the child's active depending on the parent (Doi, 1981; Stern, 1985).

Children who receive caregiving from parents that is empathic and responsive to their needs develop internal working models that enable them to be open and secure in adolescent and adult relationships (Bretherton \& Munholland, 1999; George \& Solomon, 1999; Heard \& Lake, 1997). With security and support comes an optimism toward life (Berman \& Sperling, 1994). Higher levels of parental support (caring, closeness, affection) lead to higher self-esteem, more social competence, and better psychological adjustment. In a negative family connection process, parental neglect, rejection or abuse, creates a cold, rejecting or hostile family climate, and inhibits both self-esteem and the ability to trust. This negative process is described in attachment literature as "insecure attachment" (Ainsworth, Blehar, Waters, \& Wall, 1978; Bartholomew \& Horowitz, 1991; Bowlby, 1980).

Figure 1. Family Connection and Family Individuation Processes

\section{Connection (affection; trust)}

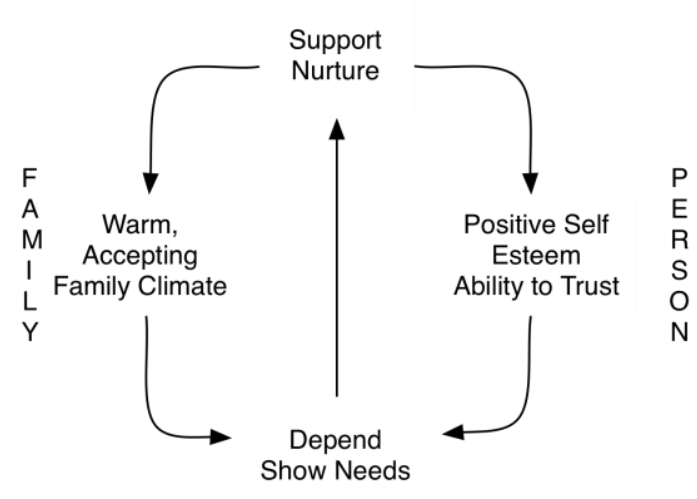

\section{Individuation (respect; autonomy)}

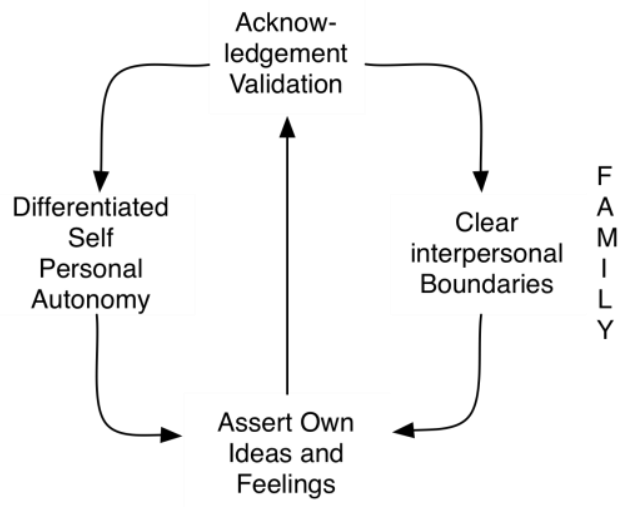

Family individuation. Just as people have a need to be cherished and nurtured, they also have a need to be autonomous and effective (Barber \& Schluteman, 2008; Erikson, 1963; Joussemet, Landry, \& 
Koestner, 2008). As toddlers begin to be capable of independent action, most parents partially refocus their caregiving actions on autonomy and effectiveness needs (Brazelton \& Cramer, 1990; Mahler, Pine, \& Bergman, 1975). The dynamic complementarity of parental caregiving with child self-efficacy is referred to as an individuation relationship (see Figure 1).

Autonomy is a prominent developmental process in adolescence and young adulthood that is fostered by family individuation (Grotevant \& Cooper, 1998; M McGoldrick, Carter, \& Garcia-Preto, 2010). To the extent that parents promote an individuated family system with clear interpersonal boundaries, where members are encouraged to think for themselves, speak for themselves, and accept others' differences, children develop their capacity for autonomous action and learn how to direct their efforts effectively toward mastering the environment (Bowen, 1978; Grotevant \& Cooper, 1985; Kerr \& Bowen, 1988). Autonomy increases as the child's assertion of ideas and feelings is met by validation and acknowledgement by parents and as family members are comfortable with independence and with differences between them (D. C. Bell \& Bell, 1983; Grotevant \& Cooper, 1985; Regalia et al., 2013).

Clear interpersonal boundaries lead the child to develop a differentiated self and a capacity for autonomous action (Garber \& Little, 2001; Karpel, 1976; Murdock \& Gore Jr., 2004; Stierlin, 1976), learning how to direct their efforts effectively toward mastering the environment, and supporting their sense of psychological well-being (Bohlander, 1999; Tuason \& Friedlander, 2000). In a negative individuation process, invalidation and mystification have the effect of decreasing comfort with individual differences and blurring interpersonal boundaries, leading in turn to less accurate interpersonal perception. In this environment, it is difficult for the child to form a differentiated self or a sense of personal autonomy. If an appropriate parent-child boundary is "dissolved" (Fullinwider-Bush \& Jacobvitz, 1993) or if the child is "triangled" into the parental sub-system to stabilize or resolve a tension in the marriage (L. G. Bell, Bell, \& Nakata, 2001), her own development may be delayed or inhibited.

Connection-Individuation complementarity. Researchers and theorists acknowledge the importance of connection, individuation, and related concepts for understanding the family-individual interface (Benson \& Deal, 1995). However the association between connection and individuation has been theoretically problematic. Connection and individuation are sometimes described as independent processes (D. C. Bell \& Bell, 1983; P. L. Bengtson \& Grotevant, 1999; Grotevant \& Cooper, 1998). However, they have also been conceptualized as opposite ends of one continuum, with a mid-range balance between connection and individuation seen as the healthier position (Minuchen, 1974; Olson, 1993). Fingerman (2001), on the other hand, considers the emotional 
closeness of connection and the healthy distance of parent-child individuation to be at the same end of one dimension of family health. Though connection and individuation are often empirically related, they are viewed here as separate and complementary processes (L. G. Bell \& Bell, 2009b; L. G. Bell et al., 2007). In our data, the measures of individuation and connection have a positive correlation, but there are outliers - families scoring high on one and low on the other. High connection without individuation looks like enmeshment; high individuation without connection presents as cold and logical (L. G. Bell et al., 2007).

\section{Using Response Pattern to Measure Family Coalitions}

The first of three examples of non-transparent research focuses on triangulation of a child into the marital system and its effects on the child. To test a theory about the effect of a certain pattern of family coalitions on development of an adolescent child, we developed a covert method to measure the coalition pattern. The method involves constructing a covert proxy for family coalitions, a method that uses data seemingly collected for a different purpose but that nevertheless allows measurement of the concept of interest. We describe here a method that uses patterns in individual data to measure the triangulation of an adolescent by the parents, a family level concept.

Sociologists have often noted the instability of the dyad in the face of conflict or stress (Coser, 1956; Simmel, 1955). The instability may be addressed in a number of ways, depending on the culture, the history of the dyadic relationship, and their problem-solving skills. As two-person relationships tend toward instability, a third person may be drawn in to stabilize the system (Toker, 1972), a process called triangulation (Bowen, 1978). Triangulation is an ubiquitous pattern in human and even nonhuman relationships (Harcourt \& De Wall, 1992). In the family any individual, parent, child or grandparent, may be triangled (Kerig, 2005); a common example would be a parent pulled in to resolve a conflict between two children. When the marital dyad becomes unstable, triangulation might occur to stabilize the marital system. Parents, for example, may avoid the tension in the marital relationship by focusing together on an adolescent's problem (distancing the child), or pull the adolescent into a coalition with one parent. Either way the parents are said to have "triangled" the adolescent. The effect of a particular family structure can be different for each child. One child pulled in to "save" the parents' marriage can leave others "free" to develop naturally (L. G. Bell \& Bell, 1982). Triangulation reflects a lower level of family individuation because it is associated with unclear interpersonal boundaries. The theory we wished to test was that triangulation would be associated with lower levels of ego development (Loevinger, 1998) in adolescents. We expected 
triangulating parents would become less able to respond to a child based on the child's self-differentiation needs, acting instead based on their own needs rather than those of the child.

As a structural property of a triad, triangulation cannot be directly observed. However, we surmised that the structure of a triangle could be inferred from patterns of individual attitudes. We assumed that emotional distances among family members would be reflected in their views of the family. The underlying assumption is that family members who are emotionally close will develop similar view of the family and those who are emotionally distant will develop more dissimilar views. The triangulation measure described here uses patterns of agreement/disagreement in response to questionnaire items describing the family. Respondents to the questionnaires have no awareness that their responses will be used to identify triangulation patterns.

Figure 2 depicts types of triangles that can form between parents and a child or adolescent in the family. A shorter edge of the triangle indicates similarity, or less disagreement, in the perception of the family. As the length of a line represents difference or disagreement between two people, the closer they are, the more they agree, the shorter the line. The balanced pattern (a) represents an individuated family without coalitions in which all views are accepted equally. The scapegoat pattern (b) represents a situation in which a child is very different in her view of the family compared to the parents' agreement. This is a pattern in which the marital dyad "pushes out" the third party to protect the dyad as a unit. Three types of triangulation (c) involve "pulling in." In the mediator pattern, the child is pulled into a position between the parents. In a cross-generational coalition, the child or adolescent is pulled in on the side of one parent (coalition of mother and child or of father and child).

Similarity was operationalized by level of agreement in the description of the family on a true-false family description instrument (Moos, 1974). For each pair of persons, the number of items on which they disagreed provided a covert measure of interpersonal emotional distance. Normalizing each relationship by dividing each distance score by the sum of the three distance scores, a global measure, adolescent triangulation, was computed as the arithmetic difference between the relationship with the highest relative distance and that with the lowest. Less balance in the triangle results in a higher score on adolescent triangulation, regardless of the direction of the imbalance. A perfectly balanced triangle would have a triangulation score of zero.

Using this indirect measure of family structure, relationships between parents and adolescents were studied in 99 U. S. and 60 Japanese families with teenage daughters. Triangled daughters in both cultures had lower scores on ego development, supporting the hypothesis that such patterns 
Figure 2. Parent-Child Patterns. Note: Line length represents difference/ disagreement.

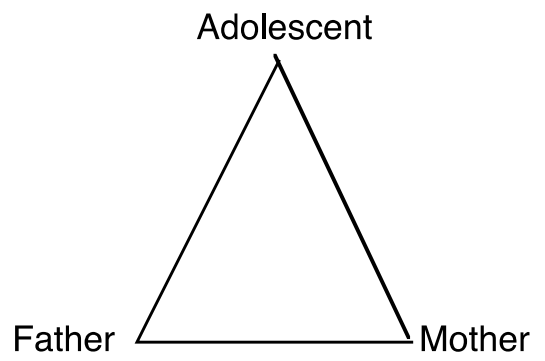

(a) Balanced

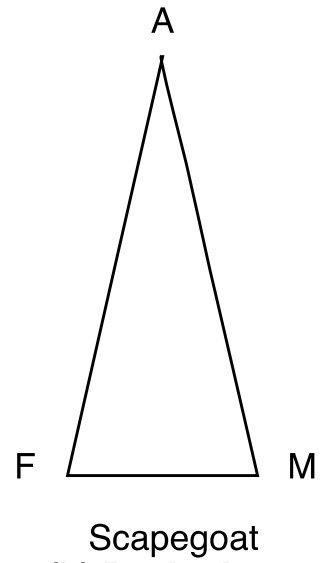

(b) Pushed out

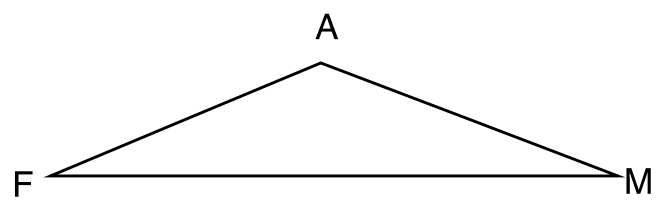

Mediator

A

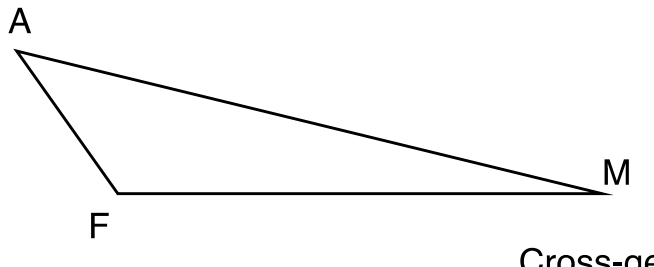

Cross-generational coalitions

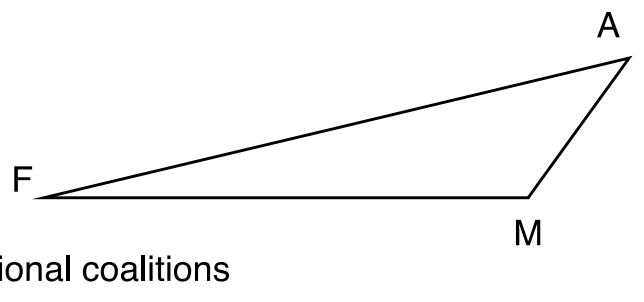

(c) Pulled In

can be detrimental to the adolescent's personal development (L. G. Bell et al., 2001). As additional support for this pattern, an association was found between parents avoiding tension in their own relationship (as measured by the Global Coding Scheme discussed below) and the triangulation score for their most triangled child.

\section{Projective Family Paper Sculpture}

Whereas the measurement theory that uses similarity and differences in attitudes to measure adolescent triangulation is completely separate from respondents' reports of overt attitudes, we now turn to a covert measure that uses a metaphor common to researchers and respondents. 
Because the metaphor is part of respondents' implicit understanding, it serves as a slightly more transparent way for respondents to describe their relationships. Projective measurement techniques in which study participants respond in non-language modalities such as pictures may reduce the cultural bias of language. Projective measures also share with open-ended responses and ethnographic interviews the increased possibility of capturing information which was not previously considered by participants or researchers. An important concept or pattern may emerge from within a collective culture, for instance, which was not conceived of in the individualistic culture's theory.

Singer and Wynne (1965) were among the first to use projective techniques to link family process to individual traits, using projective techniques such as a Family Rorschach to study the mental illness of a family member. Other examples include the sand tray (Mattson \& Veldorale-Brogan, 2010), placement of dolls to represent family members (Gerber \& Kaswan, 1971), and family sculpting in family therapy. Approaches such as these may be particularly appropriate in cross-cultural research when families are evaluated using non-language modalities. These kinds of measures side step much of the ambiguity carried by written language.

A powerful clinical technique used by family therapists for describing complex family dynamics is Family Sculpture, developed by Duhl, Kantor, and Duhl (1973). Family Sculpture is a symbolic and metaphorical use of space to describe the family system. In this exercise the sculptor places individuals in real space and uses body postures and expressions to describe the sculptor's perception of, or feelings about, specific interpersonal relationships. Individuals who have a greater difficulty encoding the emotional experience of family into coherent verbal expression are often able to express these emotional experiences nonverbally using physical metaphors such as distance, eye contact, open or fisted hands, and touch. A person or family making a sculpture may include information not in their conscious awareness that can be inferred by the therapist (Constantine, 1978).

The technique described here, the Family Paper Sculpture (FPS), preserves some of the strengths of the Family Sculpture while being useful in the research context by allowing less laborious and more precise measurements of family structure. The FPS, like the Family Sculpture, makes possible the externalization and visualization of internal realities, internal metaphorical "maps." In addition to interpersonal distance, the technique also probes experienced similarity and differences among family members and the inclusion or exclusion of family members in various family subsystems. Involving the family in a joint projective task may lead to their conveying unacknowledged or unaware family patterns through spatial metaphors, especially if the task is interesting and they become 
engaged in the process. The FPS has proven to be valuable for educational and clinical purposes as well as for research (L. G. Bell, 1986; Wedemeyer \& Grotevant, 1982).

In this activity the entire family is asked to make a family picture, an exercise in which colored disks (to show individuals and their relations), red and black lines (to show similarity and difference) and blue yarn circles (boundaries) are used to create a "picture" of the family's experience or view of itself. Specific instructions for the FPS exercise are given in L. G. Bell (1986). A photograph is taken of the FPS. A family boundary and distance between representations of individuals measure family connection; individual and relationship boundaries within the family are taken to indicate family individuation.

The FPS has been used in studies of both clinical and nonclinical populations (L. G. Bell, 1986). Bell, Ericksen, Cornwell \& Bell (1991) studied extremes of emotional closeness among family members using the FPS. Nine couples and 79 families participated in 2 studies. Closeness and distance between disks were taken to represent distinct relationship patterns (support vs. conflict; warmth vs. cold). Furthermore, extremeness may itself represent a particular relationship experience. Varying experiences of extreme closeness and extreme distance among family members may be different manifestations of the same underlying process (Lewis, Beavers, Gossett, \& Phillips, 1976). Extremes of experienced closeness were found to be associated with less family connection and less family individuation based on global coding of family interaction process. These families demonstrated less ability to resolve differences, and less warmth and support among family members. The experience of being very close, varying through time with the experience of being very distant, may be associated with disappointed attempts to achieve closeness with personal autonomy.

In cross-cultural studies, Japanese families were more likely than U.S. families to include a family boundary, implying a greater sense of family connection, and more likely to include grandparents in the picture, particularly the paternal grandmother. Japanese fathers were more likely to be depicted as isolated (L. G. Bell \& Bell, 2000). Japanese families were also more likely to make multiple pictures of the family (see Figure 3). This could have been an artifact of language as Japanese does not grammatically distinguish singular from plural (when asked to make "a picture(s)" of the family). However, careful review of all of the tapes by a cross-cultural team found the more reasonable explanation was that Japanese contextualize the family in terms of time (e.g. on vacation, in the mornings), personal criteria (e.g. personality, appearance), or interests (see Figure 3). Japanese multiple images were interpreted to reflect a textured, non-unitary experience of the family, depicting a variety of contexts, interests, or personal attributes, suggesting that Japanese 
experience the family similarly to how they experience the self, as naturally different in different contexts. This was an unexpected finding for the American members of the research team. In the U.S. families multiple images were rare and most likely associated with family members being unable to agree on a common view (L. G. Bell et al., 2004).

Figure 3. Family in Different Contexts (Japan)

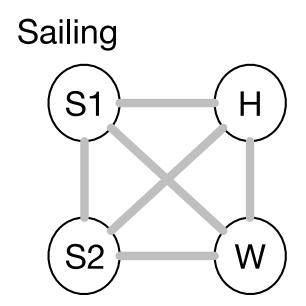

(51)

(W)
Usual life at home

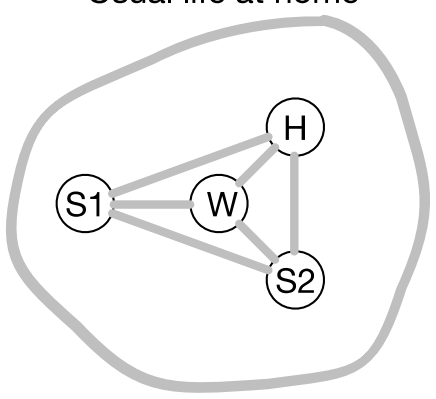

(H)
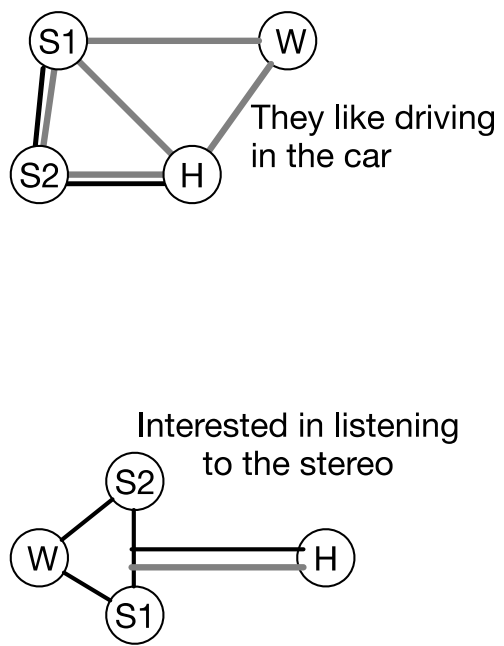

Like bird watching

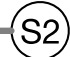

$\mathrm{H}=$ husband; $\mathrm{W}$ = wife; $\mathrm{S} 1$ = older son; $\mathrm{S} 2$ = younger son .

\section{Global Coding Scheme}

The third covert method, the Global Coding Scheme (GCS) looks at family process more than structure. Whereas the FPS uses metaphor to evaluate family structure, the GCS uses a natural process of family conversation to exhibit concepts covertly from the process and content of the conversation. Such coding can capture family interaction process at various levels of analysis from micro- to macro-analytic (D. C. Bell \& Bell, 1989). Although observational research is costly and labor-intensive, its value lies in its ability to evaluate complex family interaction patterns that contribute to family functioning and thus to useful intervention. Observational studies offer reliable and valid data unavailable from self-report measures (Markman \& Notarius, 1987). The coding of couple and family discussions has been used by a number of family researchers (e.g., Gottman \& Krokoff, 1989; Grotevant \& Cooper, 1986; Melby \& Conger, 2001). The Global Coding Scheme (L. G. Bell, Cornwell, \& Bell, 1983) to be described here is part of this tradition. We used it to code family interaction process 
around two different tasks, the one a revealed difference task (Strodtbeck, 1951) and the other, the Family Paper Sculpture task. In the revealed difference exercise, individuals are asked to consider their different answers to a true-false questionnaire describing the family and try to reach agreement. These two tasks were expected to evoke different family patterns as the one is focused on conflict, and the other is a joint family description project. As different kinds of tasks reveal different aspects of the family process (Melby et al., 1995), it was expected that having these two tasks would give us a more complete view of that process.

The structured interviews took place in families' homes. Conversation, especially when family members are feeling "at home," has an advantage in that participants easily and quickly fall into their normal speech and interaction patterns. Family members frequently forget the camera and exhibit habitual behaviors. In this third method, family interaction around a structured task is rated by coders clinically trained in family systems. Systems-sensitive coders can see patterns in the process which may be invisible to the untrained eye or to the family (D. C. Bell \& Bell, 1989).

The GCS was created to evaluate marital and family interactions on a variety of system variables. The GCS scales were derived from the BeaversTimberlawn Family Evaluation Scale (Lewis et al., 1976) and the Family Behavioral Snapshot (Meyerstein, 1979). Sample items and scales are given in Table 1.

An exploratory factor analysis was performed on the GCS, and family connection and family individuation emerged as primary factors (L. G. Bell \& Bell, 2005). The four scales which loaded highly on the family connection factor were warmth and support, depression (reversed), overt conflict (reversed), and humor. Scales loading on the family individuation factor were clear interpersonal boundaries, covert conflict (reversed), comfort with differences, and problem-solving efficiency. Family health loaded equally on both factors.

Cultural issues arise in the training of coders. When coders come from different cultures, a few hours of training may not have much of an effect. Coders who have experienced life in an American family system will bring different expectations than coders who have experienced life in a Japanese family system. It was a practical impossibility to use the same (bi-lingual, bi-cultural) coders to translate scales and code tapes from both cultures. However, for the Japanese version of the GCS, we were able to employ translators and coders from both countries with training in family systems therapy. Thus, translation and coding were done by a cross-cultural team. As a result, the Japanese GCS included measures of amae but not of power; the opposite from the U.S. GCS, which was developed solely by U.S. researchers. By using people with similar professional training we 
Table 1

Global Coding Scheme Scales

1) Warmth and support

The family has an atmosphere of openness, comfortableness, optimism \& warmth.

Family's mood is Very Cold...to...Very Warm.

Family's mood is Very Rejecting...to...Very Supportive.

Quality of laughter was warm and responsive. (not at all...to...very much).

2) Depression

The family has an atmosphere of depression, sadness, hopelessness.

Family's mood is Very Sad...to...Very Cheerful.

3) Humor

Family's use of joking and humor (none/almost none...to...very often).

Amount of laughter (none or almost none...to...very often)

4) Clear Interpersonal Boundaries

In general members take responsibility for their own actions, feeling, and thoughts, and do not take responsibility for the actions, feelings or thoughts of others.

The family has an atmosphere of overly close, stuck, over-concerned with each other (-).

Is the family's image of itself is congruent with reality? Do they see themselves as they really are? Very Congruent...to...Very Incongruent.

5) Comfort with Differences

Family seems comfortable with differences or disagreements.

Family seems to avoid differences and disagreements (-).

6) Overt Conflict

Overt conflict in the family is: Severe; impairs group functioning...to...Little or none.

7) Covert conflict

Covert conflict in the family is: Severe; impairs group functioning...to....Little or none.

How openly were feelings expressed? Very directly or openly...to...very indirectly or covertly.

Rate family as to clarity (not intensity) of disclosure of feelings and thoughts.

Very Vague \& Unclear...to...Very Clear.

8) Problem-solving Efficiency

Family's efficiency at problem solving (being able to discuss items and arrive at mutual decision on the right answers). Very Efficient...to...Very Inefficient.

9) Family Health

Very Non-Functional...to ...Very Functional. 
were able to assure some level of cross-cultural consistency in the meaning, if not the anchoring, of the scales (L. G. Bell et al., 2004).

The GCS has been used in a variety of studies, including one which found a correspondence between family closeness and peer relationship closeness (L. G. Bell, Cornwell, \& Bell, 1988). A GCS scale reflecting family connection was associated with peer closeness measured sociometrically. Most recently it has been used to explore the relationship of the midlife/adolescent family system to adult wellbeing and adult child-elder parent relationships, both among U. S. families (L. G. Bell \& Bell, 2005, 2009a, 2012), and in comparison with Japanese families (L. G. Bell, 2015). More connected and individuated families led to greater psychological well-being when the adolescents reached adulthood. Such families also led to closer adult child-elder parent relationships.

\section{DISCUSSION}

In this paper, we describe methods in which study participants are evaluated in ways that do not depend on family members' ability and/or willingness to express a concept transparently. For such concepts covert approaches to study the family may provide a perspective on family structure and process which is unavailable to the family members themselves. Based on the logic that human principles such as closeness and distance, support and conflict, are to some extent universal and people in different cultures share some common metaphors, covert projective measures avoid most of the shortcomings and cultural minefields of language. Non-language modalities or actual behavior coded by trained culturally sensitive coders remove much of the ambiguity carried by written language. Measures based on patterns in individual data or projective measures of the family can reveal family structure; coding of family interaction process by a family systems trained observer can reveal unrecognized family processes based on a theory unavailable to those whose behavior is being described (D. C. Bell \& Bell, 1989; Hampton, Beavers, \& Hulgus, 1989). These approaches may also improve the validity of measurement because they tend to side-step social desirability. If the respondent does not know the researcher's concept behind an item or exercise, the respondent's social desirability associated with the concept will not be activated. Thus potential bias is reduced.

The measures discussed here exemplify some of the strengths of covert approaches to measurement. Each of these measures has the possibility of making family structures and processes which are unconscious to family members visible to observers, e.g. by looking at response patterns on a questionnaire, observing patterns in a family projective task, or by coding interaction process. Projective measures also share with open-ended responses and ethnographic interviews the increased possibility of 
capturing information that was not previously considered by participants or researchers, an example being the contextualized pictures to describe a Japanese family. Thus these methods are more likely to leave open the exploration of new theories or hypotheses other than those which prompted the creation of the instrument. Recorded data (e.g. a taped interaction or the photograph of the picture) are then amenable to exploration of new ideas and hypotheses.

In the measurement of triangulation the researcher's theory is hidden from the respondent; thus the probability and extent of bias is much reduced. Respondents may or may not be aware of coalitions within the family, but they are not aware that those coalitions are being measured from their response patterns.

In comparison with the triangulation measures, the Family Paper Sculpture and the Global Coding Scheme are somewhat more transparent. Respondents may have some ideas about what's being measured without knowing for sure what those are or how they are being measured. Thus there is still some room for social desirability or role bias to come into play. However, when the family itself is the reporting unit, multiple family members are involved and the task itself is engaging to the family. Thus the family tasks are likely to evoke habitual family behavior. With both of these measures, the researcher is able to pick up on family structures and processes which may be outside of the awareness of the respondents themselves.

Covert measures have a particular value in cross-cultural research. Whenever any verbal item is translated into another language there will be some degree of change in meaning. All concepts exist in a web of other concepts which reflect a particular culture. Thus, the "same" word is likely to have a different connotation or "flavor" in the different cultures. It is usually meaningless to simply translate a scale and then compare two cultures on outcome measures from that scale. One could argue that this is particularly problematic when the original item was conceived in an individualistic culture and translated into the language of a collectivist culture, or vice versa. Of course, even with behavioral measures, such as the coding of family interactions, perceptions of coders will be filtered through the coder's own culture. Thus there is great value in working with cross-cultural teams throughout the entire process when doing crosscultural research (L. G. Bell et al., 2004).

As globalization and technology bring us all closer together, the importance of cross-cultural research increases, and family in its various forms is one of the fundamental commonalities across cultures. What advice can we put forward for a social scientist considering cross-cultural research and/or creating a covert measure? Being clear about the theory behind a covert measure during its development greatly enhances its potential usefulness (Grotevant, 1989). We have felt that it is very 
important to include the whole family when studying the family system, and to create tasks which engage family members. It is also important to think about what a particular task will 'pull' for from the family, e.g. frustration, a pleasant discussion. We have been committed to interview the family in their home context. While a laboratory provides more control, the home is a more naturalistic setting (Lindahl, 2001), and it is our belief that families exhibit their habitual interaction patterns more easily and thus more reliably in the family context. When considering coding of behavior, consider the relative values of coding families engaged in a task created by the researcher compared with a projective task or naturalistic home observation. Working cross-culturally, it is necessary to work with a cross-cultural team, both in the development of theory and in the creation of research instruments. The team needs to include researchers of equal status - not simply research assistants from one culture and senior colleagues from the other. Plan to take time to develop the cross-cultural team. Explore communication nuances.

Author Notes: Wave 1 research was supported by the National Institute of Mental Health (MH28190; MH29944), the University of Chicago, and the University of Houston - Clear Lake, the Texas Higher Education Coordinating Board and by Indiana University--Purdue University Indianapolis. Correspondence to: Linda G. Bell, Indiana University Purdue University Indianapolis, 425 University Blvd, Indianapolis, IN 46202 email: lgbell@iupui.edu

\section{REFERENCES}

Ainsworth, M. (1979). Infant-mother attachment. American psychologist, 34, 932-937.

Ainsworth, M., Blehar, M. C., Waters, E., \& Wall, S. (1978). Patterns of attachment: A psychological study of the strange situation. Hillsdale, NJ: Erlbaum.

Alexander, P. C., Moore, S., \& Alexander, E. R., III. (1991). What is transmitted in the intergenerational transmission of violence? Journal of Marriage and the Family, 53, 657-668.

Baldwin, M. S. (1992). Relational schemas and the processing of social information. Psychological Bulletin, 112, 461-484. doi: 10.1037/00332909.112.3.461

Barber, B. K., \& Schluteman, J. M. (2008). Connectedness in the lives of children and adolescents: A call for greater conceptual clarity. Journal of Adolescent Health, 43, 209-216. doi: doi:lo:1016/j.jadohealth.2008.01.012

Bartholomew, K., \& Horowitz, L. M. (1991). Attachment styles among young adults: A test of a four-category model. Journal of Personality and Social Psychology, 61, 226-244. 
Baumeister, R. F., \& Leary, M. R. (1995). The need to belong: Desire for interpersonal attachments as a fundamental human motivation. Psychological Bulletin, 117, 497-529. doi: http://dx.doi.org/lo.1037/o0332909.117.3.497

Bell, D. C. (2001). Evolution of parental caregiving. Personality and social psychology review, 5, 216-229.

Bell, D. C., \& Bell, L. G. (1983). Parental validation and support in the development of adolescent daughters. In H. D. Grotevant \& C. R. Cooper (Eds.), Adolescent development in the family: New directions in child development (pp. 27-42). San Francisco: Jossey-Bass.

Bell, D. C., \& Bell, L. G. (1989). Micro and macro measurement of family systems concepts. Journal of Family Psychology, 3, 137-157. doi: 10.1037/ho080530

Bell, D. C., \& Bell, L. G. (2015). Accuracy of retrospective reports of family environment. Paper presented at the Theory Construction and Research Methodology; National Council on Family Relations, Vancouver.

Bell, L. G. (1986). Using the Family Paper Sculpture for education, therapy, and research. Contemporary Family Therapy, 8, 291-300. doi: 10.1007/BFoo902930

Bell, L. G. (1989). Song without words. The Family Therapy Networker, 13, 4853.

Bell, L. G. (2015). Adolescent family affects adult wellbeing in Japan and the U.S. Archives of Scientific Psychology, 3, 138-149.

Bell, L. G., \& Bell, D. C. (1982). Family climate and the role of the female adolescent: Determinants of adolescent functioning. Family Relations, 31, 519-527. doi: 10.2307/583927

Bell, L. G., \& Bell, D. C. (2000). Japanese and U. S. marriage experiences. Journal of Comparative Family Studies, 31, 309-320.

Bell, L. G., \& Bell, D. C. (2005). Family dynamics in adolescent affect midlife wellbeing. Journal of Family Psychology, 19, 198-207. doi: 10.1037/08933200.19.2.198

Bell, L. G., \& Bell, D. C. (2009a). Effects of Connection and Individuation. Attachment and Human Development, 11, 471-490. doi: $10.1080 / 14616730903132263$

Bell, L. G., \& Bell, D. C. (2009b). Effects of family connection and family individuation. Attachment and Human Development, 11, 471-490. doi: $10.1080 / 14616730903132263$

Bell, L. G., \& Bell, D. C. (2012). Positive relationships that support elder health and wellbeing are grounded in midlife/adolescent family. Family and Community Health, 35, 276-286. doi: 10.1097/FCH.obo13e31826665a4

Bell, L. G., Bell, D. C., \& Nakata, Y. (2001). Triangulation and adolescent development in the U.S. and Japan. Family Process, 4O, 173-186. doi: 10.1111/j.1545-5300.2001.4020100173.x

Bell, L. G., Bell, D. C., Nakata, Y., \& Bell, E. M. (1996). Connection and individuality in Japan and the United States: Gender, culture, and conceptions of family health. Journal of Gender, Culture, and Health, 1, 277294.

Bell, L. G., Cornwell, C. S., \& Bell, D. C. (1983). Global Coding Scheme, ERIC (ED 248 420) Japanese scales revised by D. C. Bell, L. G. Bell, H. Dendo, K. 
Kameguchi, \& K. Kawanami. Both coding schemes available at www.familylegacies.net.

Bell, L. G., Cornwell, C. S., \& Bell, D. C. (1988). Peer relationships of adolescent daughters: A reflection of family relationship patterns. Family Relations, 37, 171-174 Check numbers. doi: 10.2307/584316

Bell, L. G., Dendo, H., Nakata, Y., Bell, D. C., Munakata, T., \& Nakamura, S. (2004). The experience of family in Japan and the United States: Working with the constraints inherent in cross-cultural research. Journal of Comparative Family Studies, 35, 351-373.

Bell, L. G., Ericksen, L., Cornwell, C. S., \& Bell, D. C. (1991). Experienced closeness and distance among family members. Contemporary Family Therapy, 13, 231-245. doi: 10.1007/BFoo891803

Bell, L. G., Meyer, J., Rehal, D., Swope, C., Martin, D. R., \& Lakhani, A. (2007). Connection and individuation as separate and independent processes: A qualitative analysis. Journal of Family Psychology, 19, 198-207.

Belsky, J. (1981). Early human experience: A family perspective. Developmental Psychology, 17, 3-23. doi: 0012-1649/81/1701-0003500.75

Bengtson, P. L., \& Grotevant, H. D. (1999). The individuality and connectedness Q-sort: A measure for assessing individuality and connectedness in dyadic relationships. Personal Relationships, 6, 213-225.

Bengtson, V. L., \& Lovejoy, M. C. (1973). Values, personality, and social structure: An intergenrational analysis. American Behavior Scientist, 16, 880-912.

Benson, M. J., \& Deal, J. E. (1995). Bridging the individual and the family. Journal of Marriage and Family, 57, 561-566.

Berman, W. H., \& Sperling, M. B. (1994). The structure and function of adult attachment. In M. B. S. W. H. Berman (Ed.), Attachment in Adults: Clinical and Developmental perspectives (pp. 1-28). New York: Guilford.

Berry, J. W. (1969). On cross-cultural comparability. International Journal of Psychology, 4, 119-128.

Berry, J. W. (1989). Imposed etics--emics--derived etics; The operationalization of a compelling idea. International Journal of Psychology, 24, 721-735.

Bohlander, R. W. (1999). Differentiation of self, need fulfillment, and psychological well-being in married women. Psychological Reports, 84, 12741280.

Bowen, M. (1978). Family therapy in clinical practice. New York: Aronson.

Bowlby, J. (1969/1982). Attachment and loss, Volume 1: Attachment (2nd ed.). New York: Basic.

Bowlby, J. (1980). Attachment and loss: Loss (Vol. 3). New York: Basic.

Bray, J. H. (1995). Family assessment: Current issues in evaluating families. Family Relations, 44, 469-477.

Bray, J. H., Williamson, D. S., \& Malone, P. E. (1984). Personal authority in the family system: Development of a questionnaire to measure personal authority in intergenerational family process. Journal of Marital and family Therapy, $10,167-178$.

Brazelton, T. B., \& Cramer, B. G. (1990). The earliest relationship: Parents, infants, and the drama of early attachment. Reading, MA: Addison-Wesley.

Bretherton, I., \& Munholland, K. A. (1999). Internal working models in attachment relationships. Pp. 89-111. In J. Cassidy \& P. Shaver (Eds.), 
Handbook of attachment: Theory, research, and clinical applications. New York: Guilford.

Bricklin, B. (1992). Data-based tests in custory evauations. American Journal of Family Therapy, 20, 254-265.

Bronstein, P., Duncan, P., D'Ari, A., Pieniadz, J., Fitzgerald, M., Abrams, C. L., . . . Oh Cha, S. Y. (1996). Family and parenting behaviors predicting middle school adjustment: A longitudinal study. Family Relations, 45, 415-426.

Carlson, C. (2001). Family Measurement Overview. In J. Touliatos, B. F. Perlmutter \& G. W. Holden (Eds.), Family measurement techniques (Vol. 2, pp. 1-10). Thousand Oaks, CA: Sage.

Caudill, W., \& Plath, D. W. (1986). Who sleeps by whom? Parent-child involvement in urban Japanese families. In T. S. Lebra \& W. P. Lebra (Eds.), Japanese Culture and Behavior: Selected Readings (pp. 247-279). Honolulu: University of Hawaii.

Chodorow, N. J. (1993). Perspectives on the use of case studies: All it takes is one. In P. A. Cowan, D. Field, D. A. Hansen, A. Skolnick \& G. E. Swanson (Eds.), Family self and society: Toward a new agenda for family research. Hillsdale, NJ: Lawrence Erlbaum.

Clingempeel, W. G., Colyar, J. J., Brand, E., \& Heatherington, E. M. (1992). Children's relationships with maternal grandparents: A longitudinal study of family structure and pubertal status effects. Child Development, 63, 14011422.

Colman, C. (1976). International family therapy: A view from Kyoto, Japan. Family Process, 25, 651-664.

Constantine, L. L. (1978). Family sculpture and relationship mapping techniques. Journal of Marriage and Family Counseling, 4, 13-23. doi: 10.1111/j.17520606.1978.tbo0508.x

Coontz, S. (2015). Revolution in intimate life and relationships. Journal of Family Theory \& Review, 7, 5-12. doi: 10.1111/jftr.12061

Coser, L. A. (1956). The functions of social conflict. Glencoe: Free Press.

Davenport-Pollock, E., Kazman, J. B., \& Deuster, P. (2014). Family functioning and stress in African American families: A strength-based approach. Journal of Black Psychology. doi: 0095798413520451

De Vos, G. A. (1993). A cross-cultural perspective: The Japanese family as a unit in moral socialization. In P. A. Cowan, D. Field, D. A. Hansen, A. Skolnick \& G. E. Swanson (Eds.), Family, Self, and Society: Toward a New Agenda for Family Research (pp. 115-142). Hillsdale, New Jersey: Lawrence Erlbaum Associates.

Doi, T. (1981). The anatomy of dependence (J. Bester, Trans.). Tokyo: Kodansha International.

Dore, R. (1958). City life in Japan. Berkeley: University of California Press.

Duhl, F., Kantor, D., \& Duhl, B. (1973). Learning, space, and action in family therapy: A primer of sculpture. Seminars in Psychology, 5, 167-183.

Eisler, R. (1987). The chalice and the blade: Our history, our future. Sal Francisco: Harper \& Row.

Epstein, C. F. (1988). Deceptive distinctions: Sex, gender, and the social order. New Haven: Yale.

Erikson, E. H. (1963). Childhood and Society. New York: Norton. 
Fingerman, K. L. (2001). A distant closeness: Intimacy between parents and their children in later life. Generations, 25, 26-33.

Fisher, L., Kokes, R. F., Ransom, D. C., Phillips, S. L., \& Rudd, P. (1985). Alternative strategies for creating "relational" family data. Family Process, 24, 213-224.

Fouts, H. N., Roopnarine, J. L., Lamb, M. E., \& Evans, M. (2010). Infant social interactions with multiple caregivers: The importance of ethnicity and socioeconomic status. Journal of Cross-Cultural Psychology. doi: 0022022110388564

Fullinwider-Bush, N., \& Jacobvitz, D. B. (1993). The transition to young adulthood: Generational boundary dissolution and female identity development. Family Process, 32, 87-103.

Garber, J., \& Little, S. A. (2001). Emotional autonomy and adolescent adjustment. Journal of Adolescent Research, 16, 355-371.

George, C., \& Solomon, J. (1999). Attachment and caregiving: The caregiving behavioral system. In J. Cassidy \& P. R. Shaver (Eds.), Handbook of attachment: Theory, research, and clinical applications (pp. 649-670). New York: Guilford.

Gerber, G. I., \& Kaswan, J. (1971). Expression of emotion through family grouping schmata, distance, and interpersonal focus. Journal of Consulting and Clinical Psychology, 36, 370-377. doi: 10.1037/hoo31108

Gilligan, C. (1982). In a different voice: Psychological theory and women's development. Cambridge, MA: Harvard University Press.

Gottman, J. M. (2013). Marital interaction: Experimental investigations. Melbourne, Australia: Elsevier.

Gottman, J. M., \& Krokoff, L. J. (1989). Marital interaction and satisfaction: a longitudinal view. Journal of Consulting and Clinical Psychology, 57, 47-52. doi: 10.1037/0022-006X.57.1.47

Grotevant, H. D. (1989). The role of theory in guiding family assessment. Journal of Family Psychology, 3, 104-117.

Grotevant, H. D., \& Cooper, C. R. (1985). Patterns of interaction in family relationships and the development of identity exploration. Child Development, 56, 415-428.

Grotevant, H. D., \& Cooper, C. R. (1986). Individuation in family relationships. Human Development, 29, 82-100. doi: 10.1159/000273025

Grotevant, H. D., \& Cooper, C. R. (1998). Individuality and connectedness in adolescent development: Review and prospects for research on identity, relationships, and context. In E. Skoe \& A. von der Lippe (Eds.), Personality development in adolescence: A cross national and life span perspective (pp. 3-37). London: Routledge \& Kegan Paul.

Hampton, R. B., Beavers, W. R., \& Hulgus, Y. F. (1989). Insiders' and outsiders' views of family. Journal of Family Psychology, 3, 118-136. doi: 10.1037/hoo80536

Harcourt, A. H., \& De Wall, F. B. M. (1992). Coalitions and alliances in humans and other animals. Oxford, UK: Oxford University Press.

Hardy, K. V., \& Laszloffy, T. A. (1995). Deconstructing race in family therapy. Journal of Feminist Family Therapy, 5, 5-33. 
Heard, D., \& Lake, B. (1997). The challenge of attachment for caregiving. London: Routledge.

Hsu, F. L. K. (1985). The self in cross-cultural perspective. In A. J. Marsella, G. De Vos \& F. L. K. Hsu (Eds.), Culture and self (pp. 24-55). London: Tavistock.

Jacob, T., Tennenbaum, D., Bargiel, K., \& Cseilhamer, R. A. (1995). Family interaction in the home: Development of a new coding system. Behavior Modification, 19, 147-169.

Joussemet, M., Landry, R., \& Koestner, R. (2008). A self-determination theory perspective on parenting. Canadian Psychology/Psychologie Canadienne, 49, 194-200. doi: http://dx.doi.org/10.1037/0012754

Karpel, M. (1976). Individuation: From fusion to dialogue. Family Process, 15, 65-82.

Kawai, H. (1988). The Japanese psyche: Major motifs in the fairy tales of Japan (Hayao Kawai and Sachiko Reece, Trans.). Dallas: Spring Publications.

Kerig, P. K. (2005). Contributions of the investigation of boundary dissolution to the understanding of developmental psychopathology and family process. In P. K. Kerig (Ed.), Implications of parent-childboundary dissolution for developmental psychopathology. Binghamton, NY: Haworth.

Kerr, M. E., \& Bowen, M. (1988). Family evaluation. New York: Norton.

Larson, R. W., \& Almeida, D. M. (1999). Emotional transmission in the daily lives of families: A new paradigm for studying family process. Journal of Marriage and Family, 61, 5-20.

Laurenceau, J., \& Bolger, N. (2005). Using diary methods to study marital and family processes. Journal of Family Psychology, 19, 86-97.

Lebra, T. S. (1976). Japanese patterns of behavior. Honolulu: University of Hawaii Press.

Lewis, J. W., Beavers, W. R., Gossett, J. T., \& Phillips, V. A. (1976). No single thread: Psychological health in family systems. New York: Brunner/Mazel.

Lindahl, K. M. (2001). Methodological issues in family observational research. In P. K. Kerig \& K. M. Lindahl (Eds.), Family observational coding systems: Resources for systemic research (pp. 23-32). Mahway, NJ: Lawrence Earlbaum.

Loevinger, J. (1998). Reliability and validity of the SCT. In J. Loevinger (Ed.), Technical foundations for measuring ego development: The Washington University sentence completion test (pp. 29-40). Mahwah, NJ: Erlbaum.

Maccoby, E. E., \& Jacklin, C. N. (1974). The psychology of sex differences, Vol. 1. Readwood City, CA: Stanford University Press.

Mahler, M. S., Pine, F., \& Bergman, A. (1975). The psychological birth of the human infant. New York: Basic.

Markman, H. J., \& Notarius, C. I. (1987). Coding marital and family interaction: Current status. In T. Jacob (Ed.), Family interaction and psychopathology. New York: Springer.

Matsumoto, D. (2002). The new Japan: Debunking seven cultural stereotypes. Boston: Nicholas Brealey Publishing.

Mattson, D. C., \& Veldorale-Brogan, A. (2010). Objectifying the sand tray: An initial example of three-dimensional art image analysis for assessment. The Arts in Psychotherapy, 37, 90-96. doi: 10.1016/j.aip.2010.02.006 
McGlodrick, M., Giordano, J., \& Garcia-Preto, N. (2005). Ethnicity and family therapy (3rd ed.). New York: Guilford.

McGoldrick, M., Carter, B., \& Garcia-Preto, N. (2010). The expanded family lIfe cycle: Individual, family, and social perspectives, 4th Ed. New Jersey: Pearson.

McGoldrick, M., Marsh Schlesinger, M., Hines, P., Lee, E., Chan, J., Almeida, R., . . . Petry, S. (2004). Mourning in different cultures: English, Irish, African American, Chinese, Asian Indian, Jewish, Latino and Brazilian. In F. Walsh \& M. McGoldrick (Eds.), Living beyond loss: Death in the family (2 ed.). New York: Norton.

Melby, J. N., \& Conger, R. D. (2001). The Iowa Family Interaction Rating Scales: Instrument summary. In P. K. Kerig \& K. M. Lindahl (Eds.), Family observational coding systems: Resources for systemic research (pp. 33-58). Mahwah, New Jersey: Lawrence Erlbaum Associates.

Melby, J. N., Ge, X., Conger, R. D., \& Warner, T. D. (1995). The importance of task in evaluating positive marital interactions. Journal of Marriage and the Family, 57, 981-994.

Meyerstein, I. (1979). The Family Behavioral Snapshot: A tool for teaching family assessment. American Journal of Family Therapy, 7, 48-56.

Mikulincer, M., \& Shaver, P. R. (2007). Attachment in adulthood: Structure, dynamics, and change. New York: Guilford.

Miller, I. W., Epstein, N. D., Bishop, D. S., \& Keitner, G. I. (1985). The McMaster Family Assessment Device: Reliability and validity. Journal of Marital and family Therapy, 11, 345-356. doi: 10.1111/j.1752-0606.1985.tbooo28.x

Minuchen, S. (1974). Families and family therapy. Cambridge: Harvard.

Moos, R. H. (1974). Family Environment Scale. Palo Alto: Consulting Psychologists Press.

Murdock, N. L., \& Gore Jr., P. A. (2004). Stress, coping, and differentiation of self: A test of Bowen theory. Contemporary Family Therapy, 26, 319-335.

Murry, V. M., Smith, E. P., \& Hill, N. E. (2001). Race, ethnicity and cuture in studies of families in context. Journal of Marriage and Family, 63, 911-914. doi: 10.1111/j.1741-3737.2001.00911.x

Nomura, N., Noguchi, Y., Saito, S., \& Tezuka, I. (1995). Family characteristics and dynamics in Japan and the United States: a preliminary report from the Family Environment Scale. International Journal of Intercultural Relations, 19, 59-86.

Olson, D. H. (1986). Circumplex Model VII: Validation studies and FACES III. Family Process, 25, 337-351.

Olson, D. H. (1993). Circumplex model of marital and family systems: Assessing family functioning. In F. Walsh (Ed.), Normal family process (2nd ed., pp. 104-137). New York: Guilford Press.

Olson, D. H. (2002). Circumplex model of marital and family systems. Journal of Family Therapy, 22, 144-167. doi: 10.1111/j.1545-5300.1979.00003x

Oyserman, D., Coon, H. M., \& Kemmelmeier, M. (2002). Rethinking individualism and collectivism: Evaluation of theoretical assumptions and meta-analyses. Psychological Bulletin, 126, 3-72. doi: 10.1037/00332909.128.1.3 
Paley, B., Cox, M. J., \& Kanoy, K. W. (2001). The young family interaction coding system. In P. K. Kerig \& K. M. Lindahl (Eds.), Family Observational Coding Systems: Resources for Systemic Research. Mahwah, NJ: Lawrence Earlbaum

Panksepp, J. (1998). Affective neuroscience: The foundations of human and animal emotions. New York: Oxford University Press.

Pinsof, W., Lebow, J., Zinbarg, R., Knoblock-Fedders, L., Friedman, G., Mann, B., . . . Goldsmith, J. (2005). Systemic Therapy Inventory of Change (STIC). Evanston, IL.

Ransom, D. C., Fisher, L., Phillips, S. L., Kokes, R. F., \& Weiss, R. (1990). The logic of measurement in family research. In T. W. Draper \& A. C. Marcos (Eds.), Family variables: Conceptualization, measurement and use (pp. 4863). New York: Sage.

Regalia, C., Manzi, C., \& Scabini, E. (2013). Individuation and differentiation in families across cultures. In M. Fine \& F. D. Fincham (Eds.), Handbook of family theories: A content-based approach (pp. 437-456). New York: Psychology Press.

Roland, A. (1988). In search of self in India and Japan: Toward a cross-cultural psychology. Prinston, NJ: Princeton University.

Rueter, M. A., \& Conger, R. D. (1995). Interaction style, problem-solving behavior, and family problem-solving effectiveness. Child Development, 66, 98-115.

Russell, A., Mize, J., \& Saebel, J. (2001). Coding the social dimentions of parenttoddler play from a vertical/horizontal perspective. In P. K. Kerig \& K. M. Lindahl (Eds.), Family observational coding systems: Resources for systemic research. Mahwah, NJ: Lawarence Erlbaum.

Salovey, P., \& Singer, J. (1989). Mood congruency effects in recall of childhood versus recent memories. Journal of Social Behavior and Personality, 4, 99120.

Sampson, E. E. (2001). Reinterpreting individualism and collectivism: Their religious roots and monologic versus dialogic person-other relationship. American psychologist, 55, 1425-1432.

Sherman, R., \& Fredman, N. (2013). Handbook of measurements for marriage and family therapy. London: Routledge.

Simmel, G. (1955). Conflict and the web of group affiliations (Kurt H. Wolff \& Reinhard Bendix, Trans.). New York: Free Press.

Simpson, J. A., \& Rholes, W. S. (2015). Attachment theory and research: New directions and emerging themes. New York: Guilford.

Singer, J. A., \& Salovey, P. (1988). Mood and memory: Evaluating the network theory of affect. Clinical Psychology Review, 8, 211-251.

Sotile, W. M., Julian, A., Henry, S. E., \& Sotile, M. O. (1988). Family Apperception Test Manual. Los Angelos.

Steinglass, P. (1980). Assessing families in their homes. The American Journal of Psychiatry, 137, 1523-1529.

Stern, D. N. (1985). The interpersonal world of the infant: A view from psychoanalysis and developmental psychology. New York: Basic. 
Stierlin, H. (1976). The dynamics of owning and disowning: Psychoanalytic and family perspectives. Family Process, 15, 277-288. doi: 10.1111/j.15455300.1976.00277.x

Strodtbeck, F. L. (1951). Husband-wife interaction over revealed differences. American Sociological Review, 16, 468-473.

Tamura, T., \& Lau, A. (1992). Connectedness versus separateness: Applicability of family therapy to Japanese families. Family Process, 31, 319-340.

Tannen, D. (1990). You just don't understand: Women and men in conversation. New York: Ballantine.

Thevenin, T. (1987). The family bed. Wayne, NJ: Avery.

Toker, E. (1972). The scapegoat as an essential group phenomenon. International Journal of Group Psychotherapy, 22, 320-332.

Touliatos, J., Perlmutter, B. F., \& Straus, M. A. (1990). Handbook of family measurement techniques. Newbery Park, CA: Sage.

Touliatos, J., Perlmutter, B. F., \& Straus, M. A. (Eds.). (2001). Handbook of family measurement techniques: Abstracts (Vol. 1). Newbery Park, CA: Sage.

Tuason, M. T., \& Friedlander, M. L. (2000). Do parents' differentiation levels predict those of their adult children? And other tests of Bowen theory in a Philippine sample. Journal of Consulting Psychology, 47, 27-35.

van de Vijver, F., \& Leung, K. (1997). Methods and data analysis for crosscultural research. Thousand Oaks, CA: Sage.

Vogel, E. (1963). Japan's new middle class. Berkeley, CA: University of California Press.

Webb, E. J., Campbell, D. T., Schwartz, R. D., \& Sechrest, L. (1966). Unobtrusive measures. Thousand Oaks, CA: Sage.

Wedemeyer, N. V., \& Grotevant, H. D. (1982). Mapping the family system: A technique for teaching family systems theory concepts. Family Relations, 31, 185-193. doi: 10.2307/584396

White, J. M., Klein, D. M., \& Martin, T. F. (2015). Family theories: An introduction (4th ed.). Los Angeles: Sage. 